\title{
Association of 1078 del T cystic fibrosis mutation with severe disease
}

P Moullier, M Jéhanne, M P Audrézet, B Mercier, C Verlingue, I Quéré, H Guillermit, O Raguénès, V Storni, G Rault, C Férec

\begin{abstract}
Apart from the high frequency of the $\Delta$ F508 mutation $(81 \cdot 81 \%)$ in Breton cystic fibrosis chromosomes, one mutation, $1078 \mathrm{del} T$, is also observed frequently $(4.96 \%)$ in this group, in comparison with the rest of the French where it occurs with a frequency of $0.57 \%$. These two mutations account for more than $86.5 \%$ of the total CF mutations identified on Breton chromosomes. We have conducted an unblinded retrospective analysis of 25 patients with the 1078 del $T$ mutation and compared their phenotypes with those of a group of $70 \Delta$ F508 homozygous patients. Both groups of patients had the same ethnic origin and were regularly attending the same $C F$ centre in Brittany, which makes this sample highly homogeneous despite the small size. The 1078 del $T$ mutation appeared to be associated with severe presentation of the disease with, however, a trend to reduced mortality and less Pseudomonas aeruginosa colonisation.
\end{abstract}

(f Med Genet 1994;31:159-161)

Cystic fibrosis (CF) is the most common lethal autosomal recessive disorder affecting Caucasian populations, with an incidence of 1 in 2500 live births. ${ }^{1}$ The CF gene encodes for a $170 \mathrm{kDa}$ transmembrane regulator (CFTR) responsible for cAMP dependent chloride chanel activity. ${ }^{2-4}$ The most frequent CFTR mutation is the deletion of a phenylalanine residue at codon $508(\Delta \mathrm{F} 508)$ of exon 10 , an exon encoding part of the first nucleotide binding fold of CFTR. ${ }^{5}$

In the Celtic population of Brittany, $\Delta \mathrm{F} 508$ is present on more than $81 \%$ of CF chromosomes. The second most frequent mutation among the Bretons, 1078 del T, occurs on exon 7 , which encodes part of the first transmembrane domain, at a frequency of $4.96 \%$. Through the Cystic Fibrosis Genetic Analysis Consortium, more than 300 different mutations have been reported. This renders genotype/phenotype correlation difficult to perform for rare mutations. In the present study, we document the clinical profile of $25 \mathrm{CF}$ patients carrying the 1078 del $\mathrm{T}$ deletion, representing $61 \%$ of the total 1078 del $\mathrm{T}$ chromosomes worldwide (personal communication). This group was also compared to $70 \Delta$ F508 homozygotes.

\section{Patients and methods}

PATIENTS

This study is an unblinded retrospective analysis of $251078 \mathrm{del} T$ patients seen on a regular basis at the CF Centre Hélio Marin in Roscoff, Brittany. Data concerning clinical presentation included height, weight, age at diagnosis, age at first infection with Pseudomonas aeruginosa, and history of meconium ileus. Information on pulmonary status included percent predicted forced vital capacity (FVC), percent predicted forced expiratory volume in one second $\left(\mathrm{FEV}_{1}\right)$, both parameters tested in a stable period. Categorical (yes/no) data regarding pancreatic sufficiency, meconium ileus, chronic presence of Pseudomonas aeruginosa colonisation, and liver involvement were studied.

Of the 1078 del $\mathrm{T}$ CF patients, $8 \%(2 / 25)$ were homozygous, $64 \%(16 / 25)$ were carrying the $\Delta$ F508 mutation on the other chromosome, and the remaining $28 \%(7 / 25)$ were compound heterozygotes (1078 del $\mathrm{T} /$ other mutation). In the latter group, we found associated with the $1078 \mathrm{del} \mathrm{T}$ mutation one $\mathrm{R} 1066 \mathrm{H}$, one 1221 del CT, one W846X, one 1717-1 G $\rightarrow$ A, two $4005+1 \mathrm{G} \rightarrow \mathrm{A}$, and one G551D.

\section{GENETIC ANALYSIS}

The strategies that we used include haplotype determination for the $\Delta \mathrm{F} 508 \mathrm{CF}$ chromosomes, denaturing gradient gel electrophoresis (DGGE), and DNA sequencing for the remaining non- $\Delta F 508 \mathrm{CF}$ chromosomes, as previously described. ${ }^{78}$ We have identified $98 \%$ of the molecular defects in our CF chromosomes and three mutations $(\Delta \mathrm{F} 50881 \cdot 81 \%$, $1078 \mathrm{del} \mathrm{T}=4.96 \%$, and $\mathrm{G} 551 \mathrm{D}=4 \cdot 13 \%$ ) account for $90.90 \%$ of these molecular abnormalities. ${ }^{910}$

\section{STATISTICS}

The risk ratio ( $\Delta \mathrm{F} 508 / 1078$ del $\mathrm{T})$ was calculated and represents an estimate of the relative risk of exposure. The Mann-Whitney $U$ test for unpaired differences was used to compare continuous data; a $5 \%$ level of significance was chosen (p).

\section{Results}

The comparison between clinical parameters of $1078 \mathrm{del} T$ patients and those for $\Delta \mathrm{F} 508$ homozygotes is shown in tables 1 and 2 and the figure. 
Table 1 Comparison of either $1078 \mathrm{del} T$ or $G 551 D$ mutation with $4 F 508 / \Delta F 508$ using continuous variables

\begin{tabular}{|c|c|c|c|}
\hline Variable & $\begin{array}{l}\triangle F 508 / \triangle F 508 \\
\operatorname{Mean}(S D)\end{array}$ & $\begin{array}{l}1078 \mathrm{del} \mathrm{T} \\
\operatorname{Mean}(S D)\end{array}$ & $p$ value \\
\hline 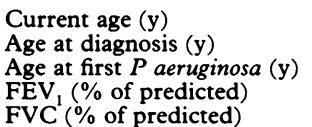 & $\begin{array}{r}12 \cdot 5(6 \cdot 5)[70] \\
2 \cdot 0(3 \cdot 0)[62] \\
8 \cdot 0(6 \cdot 0)[44] \\
62 \cdot 0(29 \cdot 0)[55] \\
72 \cdot 0(25 \cdot 0)[55]\end{array}$ & $\begin{array}{r}11 \cdot 5(7 \cdot 0)[25] \\
3 \cdot 7(6 \cdot 0)[16] \\
8 \cdot 8(7 \cdot 0)[9] \\
67 \cdot 2(23 \cdot 5)[17] \\
75 \cdot 2(18 \cdot 0)[17]\end{array}$ & $\begin{array}{l}\text { ND } \\
>0.1 \\
>0.1 \\
>0.1 \\
>0.1\end{array}$ \\
\hline
\end{tabular}

ND $=$ not determined.

[]$=$ total number of patients.

Table 2 Comparison of either $1078 \mathrm{del} T$ or $G 551 D$ mutation with $\triangle F 508 / \Delta F 508$ using categorical variables

\begin{tabular}{llrl}
\hline Condition & $\Delta F 508 / \Delta F 508$ & 1078 del $T$ & Risk ratio \\
\hline \% with onset <6 mth & $61(62)$ & $62(16)$ & $1 \cdot 1$ \\
$\%$ with pancreatic sufficiency & $3(70)$ & $0(25)$ & - \\
$\%$ with liver involvement & $12(69)$ & $8(24)$ & $1 \cdot 1$ \\
$\%$ with chronic P aeruginosa & $70(66)$ & $48(23)$ & $1 \cdot 5$ \\
$\%$ Meconium ileus & $21(70)$ & $14(18)$ & $1 \cdot 5$ \\
$\%$ Mortality & $19(70)$ & $4(25)$ & $4 \cdot 7$ \\
\hline
\end{tabular}

()$=$ total number of patients.

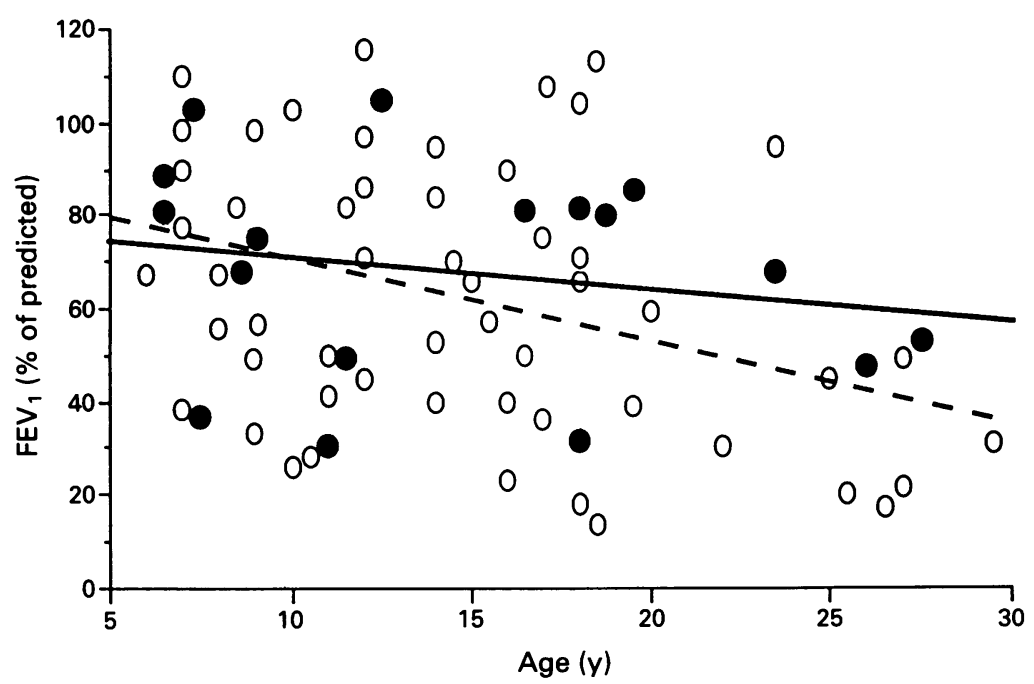

Forced expiratory volume in one second $\left(F E V_{1}\right)$ plotted against age in individual patients according to genotype group. The dashed line denotes the regression line for the patients who had the $\triangle F 508 / \triangle F 508$ genotype (open circles). The solid line denotes the regression line for the group who had the 1078 del T mutation (filled circles).

CONTINUOUS VARIABLES (TABLE 1 )

The mean age of the two groups was similar, confirming appropriate matching. There were no significant differences between the groups for any of the variables. For instance, FVC and $\mathrm{FEV}_{1}$ were used to assess pulmonary status (table 1, figure). Because of the strong dependence of lung function on age, we obtained the least square regression line (lung function variable $v$ age) from $\Delta \mathrm{F} 508$ patient data and compared it with that obtained from the $1078 \mathrm{del} \mathrm{T}$ group. Although data from both groups showed an equivalent degree of dispersed distribution, this method allowed a rough estimation and comparison of mean values for each group at any given age. The result of this analysis showed no difference $(p>0 \cdot 1)$ between patients from the two different groups who were old enough for lung function testing. When plotted against ideal weight and height (that is, those observed in the French population), 1078 del T CF patients showed reduced scores, particularly for weight in CF males. However, the curves obtained for these patients were identical to those for $\Delta \mathrm{F} 508$ homozygotes (data not shown). In addition, a moderate aggravation of disease during puberty was noted in both groups.

CATEGORICAL VARIABLES

Data for each of the categorical outcome variables are shown in table 2. The two groups were no different with regard to liver involvement and pancreatic status. Patients carrying the 1078 del $\mathrm{T}$ mutation had a reduced frequency of meconium ileus (14\% $v 21 \%)$. Seventy percent of the $\Delta \mathrm{F} 508$ homozygotes were chronically colonised with $P$ aeruginosa and the incidence was only $48 \%$ in the $1078 \mathrm{del}$ $\mathrm{T}$ group (table 2). Finally, $13 \Delta \mathrm{F} 508$ patients out of $70(19 \%)$ have died at ages ranging from 3 to 27 years. In the 1078 del $\mathrm{T}$ group, only one patient $(4 \%)$ died at the age of 10 (mean age $=11.5$ years $v 12.5$ for $\Delta \mathrm{F} 508 / \Delta \mathrm{F} 508)$.

Clinical data of the 1078 del $T /$ non- $\Delta$ F508 heterozygotes were indistinguishable from the remaining $1078 \mathrm{del} \mathrm{T}$ CF patients ( $1078 \mathrm{del} \mathrm{T/}$ $\Delta F 508)$ as well as from the $\Delta F 508$ homozygote group.

\section{Discussion}

The distribution of non- $\Delta \mathrm{F} 508$ mutations with striking regional variations is probably related to founder effect or genetic drift or both. This has permitted some investigators to collect a significant number of CF patients carrying rare genotypes, as recently illustrated by Shoshani $e t a^{11}$ in the Ashkenazi Jewish population, where the W1282X mutation represents over $60 \%$ of the CF alleles, and also by Gasparini et $a l^{12}$ who reported a high incidence of the R1162X mutation (12\%) in Veneto in north east Italy. In the Celtic part of Brittany we have also observed a founder effect for the 1078 del T mutation. Evidence for this comes from analysis of the genealogical register as well as the study of intra and extragenic polymorphisms linked to these chromosomes (unpublished data). Thus, these founder effects have led to a frequency of $4.96 \%$ for the 1078 del $\mathrm{T}$ mutation in this population.

These patients are particularly homogeneous since they share an ethnic origin and regularly attend the Centre Hélio Marin of Roscoff in Brittany where they are subjected to identical clinical protocols. In this study, we have collected clinical data on these 251078 del $\mathrm{T}$ patients and have compared them with another homogeneous group of 70 patients carrying the $\Delta \mathrm{F} 508$ mutation on both alleles, also followed at the Roscoff Centre. The results obtained show that there is (1) no significant difference between the two groups regarding their pancreatic status as all are pancreatic insufficient; (2) no significant difference with respect to pulmonary function tests $\left(\mathrm{FEV}_{1}, \mathrm{FVC}\right)$ although with a trend towards improved $\mathrm{FEV}_{1}$ among the 1078 del $\mathrm{T} \mathrm{CF}$ 
patients; (3) mortality in the 1078 del $T$ patients group is only $4 \% v 19 \%$ in the $\Delta \mathrm{F} 508$ homozygotes. It is tempting to correlate this finding with a reduced predisposition to chronic Pseudomonas aeruginosa colonisation (48\%) detected in the 1078 del $\mathrm{T}$ patients compared with $70 \%$ of $\Delta \mathrm{F} 508$ patients, since prognosis is linked to the pulmonary status which in return is highly dependent on the extent of Pseudomonas colonisation and resistance to conventional treatment, as recently outlined by Kubesch $e t$ al. ${ }^{13}$ Since the demonstration of a frequent $\Delta$ F508 deletion as well as many other mutations in the CFTR gene, investigators such as Kristidis et $a l^{14}$ and others ${ }^{15}$ have tried to identify genetically determined clinical manifestations of cystic fibrosis. Despite the lack of precise genotype/phenotype correlations, pancreatic function is one symptom which appears to be genetically determined. Indeed, pancreatic sufficiency occurs in patients who have mild CFTR mutations whereas pancreatic insufficiency occurs in patients with two severe alleles such as $\Delta F 508$. Here, we show that the 1078 del $\mathrm{T}$ mutation is associated with a severe phenotype with respect to pancreatic function. According to Kristidis et al ${ }^{14}$ the 1078 del T mutation should be added to the list of severe mutations resulting from a single nucleotide deletion. The 1078 del $\mathrm{T} / \Delta \mathrm{F} 508$ heterozygotes have identical clinical presentation when compared with the $\Delta F 508$ homozygotes. Similar results have been observed for CF mutations other than $\Delta F 508$, such as G551D, R1162X, ${ }^{16}$ $\mathrm{W} 1282 \mathrm{X}, \mathrm{N} 1303 \mathrm{~K},{ }^{17}$ and G542X. This, in addition to the 1078 del $\mathrm{T}$ phenotype described in this study, is consistent with the approximate $85 \%$ frequency of CF alleles associated with a severe phenotype. However, our cohort of 1078 del T CF patients have not been studied for a long enough period of time to permit meaningful assessment of survival. Thus, it would be interesting to continue recording the progress of these patients of which the average age is 11.5 years, in order to confirm the reduced prevalence of chronic Pseudomonas aeruginosa colonisation observed in this group, along with a possible lower morbidity.

We wish to thank Chantal Baclet for assistance in preparation of the manuscript. This work was supported by the Centre Départemental de Transfusion Sanguine of Brest, the Association Française de Lutte contre la Mucoviscidose (AFLM), the Association Bretonne d'Etude et de Recherche sur la Mucoviscidose (ABER-M), and the CRITT Bretagne.

1 Boat TF, Welsh MJ, Beaudet AL. In: Scriver CR, Beaudet AL, Sly WS, Valle D, eds. The metabolic basis of inherited disease. New York: McGraw-Hill, 1989:2649-860.

2 Dalemans $W$, Barbry $P$, Champigny $G$, et al. Altered chloride ion channel kinetics associated with the $\Delta \mathrm{F} 508$ cystic fibrosis mutation. Nature 1991;354:526-8.

3 Rommens JM, Dho S, Bear CE, et al. cAMP-inducible chloride conductance in mouse fibroblast lines stably expressing the human cystic fibrosis transmembrane conductance regulator. Proc Natl Acad Sci USA 1991;88:7500-4.

4 Bear EC, Li C, Karner N, et al. Purification and functional reconstitution of the cystic fibrosis transmembrane conreconstitution of the cystic fibrosis transmembran

5 Worldwide survey of the delta F508 mutation: report from the Cystic Fibrosis Genetic Analysis Consortium. Am $\mathcal{J}$ Hum Genet 1990;47:354-9.

6 Audrézet MP, Mercier B, Guillermit H, Férec C. A mutation in exon 7 of the CFTR gene is common in the tion in exon 7 of the CFTR gene is common in the
western part of France. 7 Med Genet 1992;29:679-80.

7 Lerman LS, Silverstein K. Computational simulation of DNA melting and its application to denaturing gradient DNA melting and its application to denaturing gradient

8 Myers RM, Maniatis T, Lerman LS. Detection and localization of single base changes by denaturing gradient gel electrophoresis. Methods Enzymol 1987;155:501-27.

9 Férec C, Audrézet MP, Mercier B, et al. Detection of over $98 \%$ cystic fibrosis mutations in a Celtic population. Nature Genet 1992;1:188-91.

10 Audrézet MP, Mercier B, Guillermit $\mathrm{H}$, et al. Identification of 12 novel mutations in the CFTR gene. Hum Mol Genet 1993;2:51-4.

11 Shoshani T, Augarten A, Gazit E, et al. Association of a nonsense mutation (W1282X), the most common mutation in the Ashkenazi Jewish cystic fibrosis patients in Israel, with presentation of severe disease. Am $\mathcal{F} \mathrm{Hum}$ Genet 1992;50:222-8.

12 Gasparini P, Nunes V, Savoia A, et al. The search for South European cystic fibrosis mutations: identification of two new mutations, four variants, and intronic sequences. Genomics 1991;10:193-200.

13 Kubesch P, Dörk T, Wulbrand U, et al. Genetic determinants of airways' colonisation with Pseudomonas aeruginosa in cystic fibrosis. Lancet 1993;341:189-93.

14 Kristidis P, Bozon D, Corey M, et al. Genetic determination of exocrine pancreatic function in cystic fibrosis. Am $\mathcal{F}$ Hum Genet 1992;50:1178-84.

15 Hamosh A, King TM, Rosenstein BJ, et al. Cystic fibrosis patients bearing both the common missense mutation patients bearing both the common missense mutation
Gly $\rightarrow$ Asp at codon 551 and the $\Delta \mathrm{F} 508$ mutation are Gly $\rightarrow$ Asp at codon 551 and the $\Delta \mathrm{F} 508$ mutation are
clinically indistinguishable from $\Delta \mathrm{F} 508$ homozygotes, clinically indistinguishable from $\triangle F 508$ homozygotes, except for decreased risk
Genet 1992;51:245-50.

16 Gasparini P, Borgo G, Mastella G, Bonizzato A, Dognini $M$, Pignatti PF. Nine cystic fibrosis patients homozygous for the CFTR nonsense mutation R1162X have mild or moderate lung disease. I Med Genet 1992;29:558-62.

17 Osborne L, Santis G, Schwarz M, et al. Incidence and expression of the N1303K mutation of the cystic fibrosis (CFTR) gene. Hum Genet 1992;89:653-8. 